\title{
Comparing Lexical Bundles in Hard Science Lectures; A Case of Native and Non-Native University Lecturers
}

\section{Parvaneh Rajaeian ${ }^{1}$ \& Razieh Rabbani Yekta ${ }^{*}$}

\section{* Correspondence: \\ r_ryekta@yahoo.com \\ 1. Department of English for Foreign \\ Language, Payame Noor University (PNU)}

Received: 10 July 2021

Revision: 10 October 2021

Accepted: 19 November 2021

Published online: 20 December 2021

\begin{abstract}
Researchers stated that learning and applying certain set of lexical bundles of native lecturers by non-native lecturers would help students improve their proficiency through incidental vocabulary input. The present study shed light on the lexical bundles in hard science lectures used by Native and Non-native lecturers in international universities with the main purpose of analyzing the structural and functional similarities and differences in their usage. The secondary purpose was to finalize and present a list of explored lexical bundles employed by Native lecturers in these lectures which could be helpful for students and also Non-Native lecturers. The corpus of this study consists of five and a half hours of three different native university lecturers' lectures and about five and a half hours of three different non-native university lecturers' lectures who were teaching hard science (nuclear physics and electronic engineering). The data were analyzed using $n$-gram tool in lextutor.ca website which is a free online software to analyze the lexical bundles of more than two corpora and compare them. Functional and structural analysis gave the following results. Findings showed that lexical richness of both Native and Non-Native lecturers was not good enough to expose students to rich environments to help them improve their English proficiency. In light of structural classification, the results revealed that dependent clause fragments in addition to verb structure phrases were the most widespread and Noun phrase + of-phrase fragments were the least employed structures of the identified lexical bundles in the lectures of NonNative and Native lecturers. In terms of structural analysis, it was concluded that stance bundles were the most frequent function bundles used by both groups. Therefore, there were both similarities and differences in the structural and functional classifications of lexical bundles in the lectures of native and non-native lecturers.
\end{abstract}

Keywords: lexical bundles, frequency, $\underline{\text { structural classification, functional }}$ classification, corpus 


\section{Introduction}

Todays, there are many English language universities both in English and non-English speaking countries. Naturally, there are both native and non-native lecturers teaching in these universities and as we know, due to the steady increase in the number of students who immigrate to English speaking countries for studying and making a better life for themselves, linguistically preparing these students for life and work in these countries is very important. Improving proficiency is one of the factors that can help this happen (Ellis, 2005; Van Patten, 2003). Lecturers who are one of the most important sources of language exposure for students, have undeniable role in this field (Neely \& Cortes, 2009). According to theories of second language acquisition, language input has a positive effect on improving proficiency. These theories show that the input has to be comprehensible to the learner and modified through interactions.

In vocabulary acquisition, the Input Hypothesis (Krashen 1981, 1982) has proved that reading, listening, and analysis of teacher's talk as oral input can help incidental vocabulary learning (Tang, 2011). Vidal (2003) found that listening to lectures is one of the ways of gaining vocabulary. Lecture comprehension, frequency of word occurrence, word elaborations, and types of vocabulary were the results of greater vocabulary gain. One of the important building blocks in discourse are lexical bundles and some researchers concluded that exposing and using certain set of lexical bundles that native lecturers use would help students to enhance their proficiency through incidental vocabulary input (Tang, 2011). Applying these lexical bundles could also help them in their academic studies. The identification of such use of language formulaically could help to simply retrieve it from memory automatic association between form and meaning and is one of the final purposes in learning and hearing lexical bundles (Kashiha \& Heng, 2013).

Many non-native lecturers due to their poor proficiency in English usually use lexical bundles that need less cognitive load. Using common lexical bundles of native lecturers by non-native lecturers could help students learn and use them in work and educational environment. But researches show that non-native lecturers generally could not provide a rich lexical environment (Tang, 2011). This is an important problem which has been neglected for years but solving this problem can heavily help students. Despite emphasizing of many applied linguists on the role of lexical bundles in the production and comprehension of language, a few studies have been done on this area (Granger \& Paquot, 2010; Wray, 2002), so more researches should carry out on this area.

\subsection{Statement of the Problem}

Word combination that has specific role in making spoken and written language is one of the important areas of studies in discourse. Lexical bundles make speech and text coherent and shape meaning. In many of recent studies, lexical bundles in written language have attracted more attention and their effects on spoken language has been left over (Nesi $\&$ Basturkmen, 2006). Since one of the best patterns to improve the use of lexical bundles are the patterns that are used by native people, analyzing native lecturers' lectures can be a good source for this study. Analyzing the lectures of native lecturers and comparing them with non-native lecturers' lectures can be very helpful for students and also lecturers themselves to enrich their vocabulary domain and to learn how to use frequent lexical bundles which are used by native people.

Exposing students to the correct and suitable use of lexical bundles is also helping them unconsciously learn more lexical bundles and get familiar with the usage (Kashiha \& Heng, 2013). Ellis (2002) states that lexical bundle's frequency of occurrence helps production and acquisition of them so by exposing to lexical bundles repeatedly, learners start to make connections between that form and its meaning, developing a formula. The more formulas a learner has, the less burden on memory because the learner does not need to find the meaning between words. Researchers believe that L2 learners should be able to use common multi-word lexical units that are usually used by native speakers to not only communicate properly but also easily be accepted into that community (Crossley \& Salsbury, 2011). The purpose of this research is to compare lexical bundles in hard science lectures in case of native and non-native university lecturers. This comparison will find frequent lexical bundles that are used by native lecturers and can help non-native lecturers and students enrich their vocabulary domain. Using these frequent lexical bundles in the lectures and exposing students to useful lexical bundles will be helpful in improving their speaking ability.

\subsection{Research Questions}

Based on the descriptions introduced above, these questions were spotted on:

1. What are the patterns of lexical bundles in Native university lecturers' lectures in hard sciences? 
2. What are the patterns of lexical bundles in Non-Native university lecturers' lectures in hard science?

3. What are the similarities and differences between the patterns of lexical bundles in Native and Non-Native lecturers' lectures?

\section{Literature Review}

English has been widely used as the medium of instruction in academic courses at different levels-in face-to-face, distance learning, and online contexts in both English speaking and non-English speaking countries. Second language (L2) learners in these courses have to comprehend not only reading materials such as textbooks and research articles but also lectures, seminars, labs, and tutorials (Dang, 2018). It is essential for learners to master the words that they are likely to encounter often in a wide range of academic written and spoken texts.

\subsection{Lexical Bundles, Functional and Structural Characteristics}

Formulaic language research focusing on lexical bundles has got more attention particularly since the late 1990s. The term "lexical bundle" was first stated by Biber et al. (1999) in a chapter of the Longman Grammar of Spoken and Written English (LGSWE). Lexical bundles by the way in which they are determined are characterized, which is only based on their frequency in a corpus (Biber et al., 1999). It should be noticed that lexical bundles are something more than sequences of individual words; these sequences have pragmatic functions in discourse, and meet recurrent communicative needs (Biber \& Barbieri, 2007; Hyland, 2012; Wood, 2015). Previous studies investigated differences in the frequencies of lexical bundles by native English lecturers and non-native English lecturers in some discourses (Kashiha \& Heng, 2013, 2014; Nesi \& Basturkmen, 2006).

Several researchers (Biber, Conrad, \& Cortes, 2004; Hyland, 2008a, 2008b; Salazar, 2014) have investigated the functional characteristics of bundles in discourse. Hyland (2008) classified bundles into three primary categories: Research-oriented bundles (with subcategories of Location, Procedure, Quantification, Description, and Topic), Textoriented (with subcategories of Additive, Comparative, Inferential, Causative, Structuring, Framing, Citation, Generalization, and Objective) and Participant-oriented bundles (with subcategories of Stance and Engagement). In most of researches, structural characteristics were analyzed adopting Biber et al. (1999) taxonomy (Crossley \& Salsbury, 2011; Kwon \& Lee, 2014; Schnur, 2014).

\subsection{Background}

According to Biber and Barbieri (2007), lexical bundles have three important features that differentiate them from other kinds of expressions: being common, not being idiomatically meaningful, not representing complete structural unit. Identifying structural and functional characteristics of lexical bundles will help to know how to use them. According to previous researches (Biber, 2006, Biber \& Barbieri 2007; Hyland, 2008), it is possible to consider four major structural types of bundles:

1. Verb phrase components, which could consist of passive voice, anticipatory subjects and dependent clause - is assumed to be, it is possible that, can be seen as,

2. Noun phrase elements followed by a part of a modifier, often of a - prepositional phrase - the end of the, the extent to which, a function of the,

3. Prepositional phrases followed by prepositional or clausal elements - at the end of, of the things that, and

4. Others, usually longer structures that serve as politeness structures (Biber, 2004) - as well as the, thank you very much, what are you doing, have a nice day.

The functional classification of lexical bundles considered in this study includes the following three types of bundles, further divided into several subcategories:

1. Referential bundles: greatly similar to referential expressions in Biber and Barbieri (2007) and research oriented bundles in Hyland's (2008) classification show conceptual meanings interconnected to the description of reality:

a) time/place/text-deixis bundles - at the end of the, at the beginning of

b) Attribute bundles (specifying procedure, quantity or description of reality) - a little bit of, the use of the, the structure of the 
c) topic-specific bundles - in the curricula of, the interpretation of the

2. Discourse organizers: the term is taken from Biber and Barbieri (2007):

a) Logical relations bundles

- Transition bundles (addition/contrast) - on the other hand, in addition to the, in contrast to the

- Resultative signals - as a result of, it was found that, these results suggest that

b) Intratextual reference bundles (organizing smaller and larger stretches of discourse)

c) Framing bundles (focusing, limiting conditions on arguments) - in the case of, with respect to the, in the presence of, with the exception of

3. Attitudinal bundles convey interpersonal meanings including:

a) Stance bundles (express the evaluations and attitudes of the writer) - the fact that the, it is possible to, are more likely to

b) Interactional bundles (address readers and involve them in the argumentation) - it should be noted that, as can be seen.

\subsubsection{Native and Non-Native English Lecturers and Vocabulary Exposure}

Fitriati and Wahyuni (2018) studied lexical bundles in WhatsApp conversation between native and non-native speakers of English. They investigated the use of lexical bundles and their functions. They employed the lexical bundle taxonomy by Biber et al. (1999) and the functional types of lexical bundles by Conrad and Biber (2004). The data were derived from naturally-occurring WA conversation between a native speaker (NS Fab- pseudonym) and a nonnative speaker (NNS Yun- pseudonym) who are English language teacher professionals. The results showed that the lexical bundles produced by native and nonnative speakers of English mostly revealed Stance between the two person which includes functions of epistemic stance and attitudinal/modality stance to show intention, desire, ability, obligation, and directive. The Discourse Organizing function is also used, particularly to introduce and elaborate the topic; while the Referential Expression type is not very much used in the conversation.

Dang (2018) conducted a research on the nature of vocabulary in academic speech of hard and soft science. He believed a few researches have been done on similarities and differences between these two classes of science, especially in spoken discourse so he developed a soft science spoken word list for second language learners of soft science in English-medium universities. 1,964 most frequent and wide-ranging word-families in a 6.5 million word corpus of soft-science speech were gathered. Then he compared this list with a list from Dang's (2018) hard science spoken word list. The findings showed that the most frequent 3,000 words are important for comprehending academic speech of in soft- and hard-sciences but the value of these words in soft-sciences is greater than in hard-sciences.

Kwon and Lee (2014) have analyzed lexical bundles in the Korean non-native and native English teachers. Teachers' classroom talk corpora in terms of qualitative and quantitative characteristics were studied. The corpora in this study include total of 247,398 words complied through 62 hours of recording of EFL classes. Wordsmith 6.0 was used to study frequency, functional, and structural characteristics. In frequency analyzing, they found that non-native English teachers use repeatedly a limited number of lexical bundles and a few numbers from functional categories, e.g. stance expressions and referential expressions. The most important result was that there are not only quantitative but also qualitative differences in lexical bundle preferences between the native and the non-native teachers.

In a research by Üstünlüoglu (2007) the perception of students from native and non-native teachers was studied. The data from 311 university students and 38 native and non-native English teachers in Turkey were evaluated. A questioner with 30 items related to teaching, management, and communication roles in addition to individual features of teachers was used for this assessment. The communication role was the most important feature for them so it was concluded that from student's point of view, native teachers show better communication skills with richer vocabulary usage than non- native teachers. Further analysis of these results could help non-native teachers raise their awareness about their lack of skills. 


\subsubsection{Academic Lectures}

In two last decades, lexical bundles has got significant attention in academic writing and speaking (Adel \& Erman, 2012). Kashiha and Heng (2013) in their study tried to discover the variety of different lexical bundles in different parts of a lecture: introduction, body, and closing section. In their research they came to this result that, there are two divisions in which lecturers apply different structures and functions in the use of lexical bundles to be more comprehensive for students. The corpus of this study is 24 academic lecture transcripts taken from an online academic corpus named BASE. Two broad fields of science were considered: soft science (SS) as law, politics, and CELTE, and hard science (HS) that includes chemistry, computer, and engineering. Four-word lexical bundles have been considered the most common strings of the words in the academic genre and so in this study; the focus was on these kinds of lexical bundles.

Lexical bundles were analyzed functionally and structurally according to Biber et al.'s (2004) functional and structural classification. After analyzing frequency of lexical bundles, the writers concluded that lexical bundles are frequently used in academic lectures and they occupy a large portion of the speech but there were differences in frequency of applying lexical bundles in hard and soft science. A large number of lexical bundles are used in hard science in comparison with soft ones. There were also significant similarities and differences in structural type of the bundles used. At the end of this article, the writers stated that the differences in the form and function of lexical bundles in academic lectures of different disciplines show the necessity of improving students 'awareness towards the use of these lexical bundles in different discourses.

Lorenna, Fitriati, and Widhiyanto (2020) in a research analyzed non-native and native English teachers' talk in order to explain (1) the use of structural and functional types of lexical bundles in non-native and native English teachers' talk, (2) the similarities and differences of lexical bundles used in the talk, (3) the relation between structural and functional types of lexical bundles used in the talk. The data in this study were gathered by recording the teachers' talks during teaching and learning process. The teaching and learning process for 4 meetings; two in native English teachers' classes and two other ones in non-native ones were recorded by researchers. The writers identified the lexical bundles found in the utterances. Then, they classified the data in tables containing elements of structural and functional types of lexical bundles and analyzed them. The results demonstrated that structurally, non-native and native English teachers performed lexical bundles in form of verb phrase, dependent clause, and noun phrase and prepositional phrase. However, they used verb phrase fragments the most.

Both teachers employed lexical bundles in form of verb phrase. Functionally, they both (native and non-native) performed lexical bundles as stance expressions. Even though both groups of teachers employed the same structure and function, they were different in terms of subcategories. There was a close relationship between the structures of lexical bundles and the function they serve. The writers mentioned that the use of lexical bundles in the talk will facilitate the acquisition process of students. It is also obligatory for non-native teachers to adopt some bundles performed by the native English teacher to make their talk sound natural and fluent. Finally they concluded that it is important for teachers to use native's lexical bundles in their talk as well as raising their awareness in performing the correct bundles structurally and functionally.

\subsubsection{Academic Writings}

In a study by Esfandiari and Barbary (2017) a contrastive corpus study of lexical bundles between English writers and Persian writers in psychology research articles was analyzed. They believed knowing lexical bundles helps improve fluent linguistic production, forms the building blocks of academic discourse, and establishes membership in disciplinary communities. So they studied the 4-, 5-, and 6-word lexical bundles in a 4,370,630-word corpus consisting of RAs in psychology (RAP) divided into two sub corpora: English corpus (EC) and Persian corpus (PC). They examined the frequency and range of lexical bundles in psychology RAs, using WordSmith Tools 6.0. Four hundred and sixteen (254 4-word, 115 5-word, and 47 6-word) and 316 (116 4-word, 104 5-word, and 96 6-word) lexical

bundles were found in EC and PC, respectively. The results also implied that Persian writers applied fewer lexical bundles, using them structurally and functionally differently than did English writers.

A study was done by Vo (2019) on the use of lexical features in non-native academic writing. He used both singleword based and multi-word analyses. Vocabulary distributions and lexical bundles were studied to better understand the improvement of writing proficiency across three levels in an English Placement Test corpus (EPT) (N=1388). To compare statistical differences in the proportions of vocabulary and lexical bundle distributions among all group 
levels, inference tests for multiple population proportions were carried out. The findings showed that higher number of types, tokens, and word families were used by higher proficiency learners in comparison with lower proficiency learners. He found noun phrase-based and verb phrase based bundles with referential and stance functions in lowerlevel responses. Preposition phrase-based bundles were significantly used in higher-level written discourse. His study shows the importance of vocabulary and lexical bundles in academic writing.

A study on exploring lexical bundles in the Algerian corpus of engineering was done by Rezoug and Vincent (2018). They evaluate the frequency, structure, and function of four-word bundles used in Electrical and Electronic Engineering Master's dissertations written in English by Algerian students. They analyzed these bundles according to Hyland's (2008) framework. The results for the bundles found in these Master's dissertations were completely consistent with earlier results (Hyland, 2008) in that certain features of more 'expert' academic writing are found less frequently and they worked on grouping of bundles with the same function into 'bundle clusters' that could be an approach to the analysis of different discourses.

Shin (2019) conducted a research on the use of lexical bundles in college students' essays focusing on whether native writers always have a head start over non-native writers. According to this study, researchers have stated L2 novice/student writers focus on formulaic language typical of conversation more than L1 academic writers but they compared different types of academic writing, so do not reveal whether the L2 patterns they found are related to register or to characteristics of L2 writers, or both.so he examined the use of frequently lexical bundles on corpora of L1 and L2 novice academic writing, which were totally matched for register and writing prompts. Structural and functional analysis showed that the two groups have many common features in using bundles which use of VP-based bundles, stance-expression bundles, idiomatic PP bundles, and informal quantifying bundles were examples of this sharing.

A study on formulaic language on social science by Malik, Fazal, and Moavia (2019) was done on how lexical bundles were used differentially by native and non-native writers in the academic discourses of Ph.D. theses. The data were gathered through $200 \mathrm{Ph}$.D. theses written by non-native Pakistani and native scholars in five different fields of social science. They used a corpus tool, AntConc 3.3.5, to identify the 4-word units of lexical bundles in the corpus. The lexical bundles then were categorized in three functional categories as referential, discourse organizing, and stance. After analyzing data, they suggested that native and non-native writers used referential lexical bundles more significantly and a minimum use of discourse organizing and stance bundles with certain qualitative differences was found. The goal was to help English for Academic Purposes (EAP) scholars develop teaching materials to improve academic skills of non-native writers.

\section{Methodology}

A descriptive analytical corpus based approach was used to investigate the differences in the use of lexical bundle by Native and non-Native university lecturers in hard science. The goal was finding and comparing frequent lexical bundles in these two groups. Since in Iran we do not have many native lecturers and there is no international university and as the writer of this article has studied another major in a foreign country, Italy, it was decided to use the corpora for non-native lecturers gathered from university lecturers of that international Italian university.

\subsection{Design and Context of the Study}

The analyzed corpus here consists of five and a half hours of three different native university lecturers' and about five and a half hours of three different non-native university lecturers' lectures. While past analysis of collocations and lexical bundles has often involved the use of large-scale corpora consisting of hundreds of thousands, and even millions of words, valuable analysis has also been obtained by using much smaller corpora than can be found in literature review section. Lack of access to many resources due to filters and sanctions, this study was limited to a smaller corpus. Due to the goals of this study, all the recordings were gathered from hard science, nuclear physics, and electronic engineering. The author tried to select a fairly equal sum of the number of words both in native and non-native lecturers' lectures to avoid any probable unreliability caused by number discrepancy. Moreover, additional measures were taken to raise the consistency of the findings. For example, the author wanted to make sure that native lecturers were from an English speaking countries so tried to find pure American lecturers in the international universities in USA. 


\subsection{Participants}

There were 6 native and non-native lecturers whose lectures were used in this study. Two native lecturers were American lecturers who were teaching in university of Kentucky in the United States and they lectured on two courses in physics and the other was teaching in the University of California, Berkeley and he lectured on analog integrated circuits. The first two lectures have been recorded by a student in the class and the last lecture was downloaded from YouTube. The first non-native university lecturer' lecture was about electronic engineering by an Italian lecturer, teaching in the University of Politecnico di Torino in Italy. The second lecture was recorded by a student in a South Korea which was about semiconductor device electronics. This one was teaching in the university of INHA in South Korea and the last lecture was downloaded from YouTube which was a lecture of an Indian lecturer in Indian Institute of Technology DELHI lecturing on power electronics. A summary of the statistics for the two corpora is provided in the Table 1 .

Table 1. Demographic background of the participants

\begin{tabular}{lcc}
\hline Corpus & Number of files & Number of words \\
\hline Non-native & 6 & 18957 \\
Native & 6 & 23061 \\
\hline
\end{tabular}

\subsection{Instrument $(s)$}

There are many computer programs that are very useful and popular in analyzing lexical bundles in every corpus such as Wordsmith, and AntConc and etc. Due to some sanction problems in Iran, we had no access to these programs so we had to choose lextutor.ca website which is a free online software to analyze the lexical bundles in the corpora and compare them. The first part used in this site is $\mathrm{n}$-gram. Through this part we can pull out all the recurring word strings of the corpus up to the maximum length of five words. Clearly not every repeated word string is a meaningful unit, and not every meaningful multi-word unit is a lexicalized unit as described in the research. Therefore, this program allows inspection of each extracted string in concordance format so that its status can be determined.

We had saved all the transcripts in .doc format but the format that is acceptable by this program was .txt so we had to convert .doc files to .txt. For the purposes of this study, the n-gram output was considered a lexical bundle if it occurred more than 20 times per million words within the corpus; this frequency was chosen to distinguish lexical bundles (which are, by definition, frequently occurring) from other four-word n-grams in order to replicate the specifications used by Biber et al. (2004). In order to make the research more manageable, this study only focused on four-word lexical bundles, which is in line with previous studies that had found four-word (Biber et al., 2004; Chen, 2008; Cortes, 2002).

Another part of this site that was used and was so helpful in analyzing our corpus and comparing the characteristics of two different native and non-native lecturers' lectures was VocabProfilers. This part has four separate sections including VP-Kids, VP-Classic, VP-Compleat, and VP-Coca. Each part can be used for different kinds of corpus. The part that was suitable for our corpus in terms of the length and number of words was VP-Compleat. This part is suitable for texts with at most 200,000 characters/ 35,000 words-if you have larger files you should use VP-Compleat with Classic option. VocabProfile will tell you how many words the text contains from the following four frequency levels: (1) the list of the most frequent 1000 word families(K1), (2) the second 1000(K2), (3) the Academic Word List(AWL), and (4) words that do not appear on the other lists.

\subsection{Data Collection Procedure}

All the recorded or downloaded lectures were transcribed precisely and were written in word document for analyzing .One interesting point in making the transcript of the recorded voices was that the number of words of native lecturers' lectures compared to non-native lecturers' lectures were significantly higher in the same period of time but to make the comparison possible we had to remove some parts of the transcripts of native lecturers' lectures. The cut-off point used to account for a sequence as a lexical bundle is arbitrary. Biber et al. (1999) assumes that lexical sequences are considered lexical bundles if they occur at least 10 times per million words. 
Biber and Barbieri (2007), on the other hand, presume the cut-off frequency of 40 occurrences per million words. The criterion for frequency and distribution in this study was just like what Cortes (2004), Hyland (2008a, 2008b), and Jalali et al. (2008) adopted as a cut-off point. Sequences with the minimum occurrence of 20 times per million words were qualified as lexical bundles. To narrow down the scope of analysis, 4 -word bundles were focused on. According to Hyland (2008a), they are far more common than 5-word strings and offer a clearer range of structures and functions than 3-word bundles. To justify this decision better, Cortes (2004) believes that -many 4-word strings hold 3-word bundles in their structures.

\subsection{Data Analysis}

To achieve the preset goals of this study both native and non-naïve lecturers' lectures were analyzed separately in terms of their lexical bundles' structural and functional taxonomies. First, lexical bundles were determined in line with the frequency criteria previously set. Then, target bundles were classified in terms of their structural features according to an adapted classification from Biber et al. (1999). Later, the functional features of the target lexical bundles were analyzed. The same was done for non-native lecturers' lectures. After the structural and functional analysis had been done for both native and non-native lecturers' lectures, a comparative analysis were done on the differences between the structural and functional features existing between the lexical bundles of native and non-native lecturers' lectures. Descriptive statistics including frequency, percentages, and mean were used to analyze the data of this study.

\section{Results}

Involvement of mathematicians in applied linguistics study results in describing the vocabulary of a text more precisely. Frequency-driven numerical measuring of various kinds could be applied to analyze lexis of texts. One useful measure of complexity, a type-token ration (TTR), documents lexical richness, or variety in vocabulary. Typetoken ratio (TTR) is the total number of unique words (types) divided by the total number of words (tokens) in a given corpus. The closer the TTR ratio is to 1, the greater the lexical richness of the segment. One of the factors that has been measured in this study was TTR for each corpus to compare the lexical richness of native and non-native lecturers' lectures. As Laufer (2001) stated, beyond the use of the most frequent 2,000 words in the English language constituting the widely referred to General Service List or GSL (West, 1953) and often quoted as K1 and K2, the ratio of academic words and infrequent (off-list) words in any text is a more adequate descriptor of its lexical diversity so the researcher also tried to compare these factors along with TTR to be able to compare these two corpora more practically. In the following tables we can see the results of this analysis done by VocabProfilers.

Table 2. Descriptive statistics of productive vocabulary on NNTLs

\begin{tabular}{cc}
\hline K1 Words (1-1000) & $81.88 \%$ \\
\hline K2 Words (1001-2000) & $3.05 \%$ \\
AWL Words & $5.65 \%$ \\
Off-List Words & $9.42 \%$ \\
\hline
\end{tabular}

Table 3. Descriptive statistics of productive vocabulary on NTLs

\begin{tabular}{cc}
\hline K1 Words (1-1000) & $84.89 \%$ \\
\hline K2 Words (1001-2000) & $3.86 \%$ \\
AWL Words & $4.01 \%$ \\
Off-List Words & $7.25 \%$ \\
\hline
\end{tabular}

Results show that the largest number of different lexical bundles was established in NNLLs corpus whereas NLLs corpus contained almost the same number of lexical bundles. Since lexical bundles are usually associated with 
naturalness of expressions, NLLs were expected to contain many more bundles that NNLLs corpus. Further analyses can more precisely compare these two corpora by considering other factors like the use of K1 (1-1000) and K2 (10002000) level words, the number of AWL (Academic Word List) and words that do not appear in the other lists by native and non-native lecturers in their lectures. As can be seen there is not substantial differences in using K1 and K2 word levels between native and non-native lecturers' lectures. K1 level word for native and non-native lecturers is $84.89 \%$ and $81.88 \%$, respectively. $3.86 \%$ and $3.05 \%$ is the percentage of using K2 level word by native and nonnative lecturers. The last computed factor for the two corpora is off-list words that is higher with $9.42 \%$ for non-native lecturers compared to native ones with $7.5 \%$.

\subsection{Frequency of Lexical Bundles in Lecturers' Lectures}

After applying the exclusion criteria, the number of the identified bundles came up to 859 4-word lexical bundles, 35263 -word lexical bundles and 1144 4-word lexical bundles and 3584 3-word lexical bundles in Native and NonNative lecturers' lectures, respectively. The results of this study show that the number of 3-word lexical bundles is about five times more than 4-word lexical bundles in native lecturers' lectures and about three times in Non-native lecturers' lectures. By using N-gram program in lextuture.com, an initial list of lexical bundles was generated both for native and non-native lecturers' lectures. Applying the frequency criteria discussed in the previous section and accounting for the common lexical bundle in both corpora, a final list of 4-word lexical bundles was generated by the researcher.

Table 4. Top 25 lexical bundles in order of frequency-the final list

\begin{tabular}{|c|c|c|c|c|c|}
\hline Rk. & Frequency & Lexical bundles in NNTL & Rk. & Frequency & Lexical bundles in NTL \\
\hline 1 & 23 & I'M GOING TO HAVE & 1 & 13 & IS GOING TO BE \\
\hline 2 & 10 & SO I'M GOING TO & 2 & 8 & THE END OF THE \\
\hline 3 & 9 & IS GOING TO BE & 3 & 8 & IT"S GOING TO BE \\
\hline 4 & 9 & WE ARE GOING TO & 4 & 8 & YOU'RE GOING TO HAVE \\
\hline 5 & 7 & IN THE FORM OF & 5 & 6 & GOING TO HAVE TO \\
\hline 6 & 6 & IF I TRY TO & 6 & 6 & TO DO IS TO \\
\hline 7 & 6 & IF YOU LOOK AT & 7 & 5 & IF YOU WANT TO \\
\hline 8 & 6 & IT IS GOING TO & 8 & 4 & YOU LOOK AT THIS \\
\hline 9 & 5 & IF I LOOK AT & 9 & 4 & HAVE A LOT OF \\
\hline 10 & 5 & LET ME CALL THIS & 10 & 4 & YOU WANT TO MAKE \\
\hline 11 & 5 & AM GOING TO HAVE & 11 & 4 & GOING TO BE EQUAL \\
\hline 12 & 5 & I AM GOING TO & 12 & 4 & HAVE TO WORRY ABOUT \\
\hline 13 & 4 & AS FAR AS THE & 13 & 4 & LET'S SAY YOU HAVE \\
\hline 14 & 4 & IN THE MIDDLE OF & 14 & 4 & IF YOU LOOK AT \\
\hline 15 & 4 & IF I WANT TO & 15 & 4 & YOU WANT TO USE \\
\hline 16 & 4 & SO LET US SAY & 16 & 4 & THIS IS GOING TO \\
\hline 17 & 4 & IF WE HAVE SOME & 17 & 4 & YOU REALLY WANT TO \\
\hline 18 & 4 & I WOULD LIKE TO & 18 & 3 & WHAT YOU WANT TO \\
\hline 19 & 4 & IS SOME KIND OF & 19 & 3 & SO WHAT DO WE \\
\hline 20 & 4 & THAT IS GOING TO & 20 & 3 & WHAT DO WE DO \\
\hline 21 & 4 & WILL BE ABLE TO & 21 & 3 & YOU WANT TO DO \\
\hline
\end{tabular}




\begin{tabular}{lrrrrr}
22 & 4 & THIS IS GOING TO & 22 & 3 & GOING TO LOOK LIKE \\
23 & 4 & ARE GOING TO HAVE & 23 & 3 & WE DON'T NEED TO \\
24 & 3 & SO I HAVE TO & 24 & 3 & IT'S GOING TO LOOK \\
25 & 3 & SO IT IS LIKE & 25 & 3 & IT'S KIND OF LIKE \\
\hline
\end{tabular}

\subsection{Structural Characteristics of Target Bundles}

The adapted taxonomy of Biber et al. (1999) was the basis for the classification of the target bundles in terms of their structures. This taxonomy can be seen in Table 5 .

Table 5. The main structural type of lexical bundles in Biber (1999)

\begin{tabular}{|c|c|}
\hline Structure & Examples \\
\hline Noun phrase with of-phrase & The end of the, the nature of the, a large number of \\
\hline noun phrases with other modifier & The fact that, one of the most, the extent to which \\
\hline Propositional phrase+of & At the end of, as a result of, on the basis of \\
\hline Other propositional phrases & On the other hand, at the same time, with respect to the \\
\hline $\begin{array}{c}\text { Passive+prepositional phrase } \\
\text { fragment }\end{array}$ & Is shown in figure, is defined as the, can be found in \\
\hline Anticipatory it & It is important to, it is possible that, it was found that \\
\hline $\mathrm{Be}+$ noun/adjective phrases & Is the same as, is due to the, be the result of \\
\hline $\begin{array}{c}\text { (Verb phrase }+ \text { ) that-clause } \\
\text { fragment }\end{array}$ & studies have shown that, that there is \\
\hline $\begin{array}{c}\text { Verb / adjective +) to-clause } \\
\text { fragment }\end{array}$ & are likely to be, to be able to \\
\hline Adverbial clause fragment & as shown in figure, as it can be seen \\
\hline Pronoun / noun phrase + be $(+\ldots)$ & this did not mean that, this is not to say that \\
\hline others & As shown in figure, should be noted that, is likely to be \\
\hline
\end{tabular}

According to this taxonomy, we classified the identified bundles structurally that the distribution can be seen in Table 6, Figures 1 and 2. 
Table 6. Structural classifying of the identified lexical bundles according to Biber's taxonomy

\begin{tabular}{|c|c|c|}
\hline Structure & NNTLs & NTLs \\
\hline $\begin{array}{l}\text { Noun phrase with of- } \\
\text { phrase }\end{array}$ & & The End of The \\
\hline \multicolumn{3}{|l|}{$\begin{array}{l}\text { noun phrases with other } \\
\text { modifier }\end{array}$} \\
\hline Propositional phrase+of & In the Form of-In the Middle of & \\
\hline $\begin{array}{l}\text { Other propositional } \\
\text { phrases }\end{array}$ & As Far As the & \\
\hline \multicolumn{3}{|l|}{$\begin{array}{l}\text { Passive+prepositional } \\
\text { phrase fragment }\end{array}$} \\
\hline Anticipatory it & It is going to-so it is like & $\begin{array}{l}\text { It's going to be-it's going to look-it's } \\
\text { kind of like }\end{array}$ \\
\hline $\begin{array}{c}\text { Be+noun/adjective phrases } \\
(\text { Verb phrase }+) \text { that-clause } \\
\text { fragment }\end{array}$ & Is going to be-is some kind of & Is going to be \\
\hline $\begin{array}{l}\text { Verb / adjective }+ \text { ) to- } \\
\text { clause fragment }\end{array}$ & $\begin{array}{l}\text { will be able to- I would like to-so I } \\
\text { have to-if I try to-If I want to }\end{array}$ & $\begin{array}{l}\text { going to have to-to do is to-you really } \\
\text { want to-we don't need to-if you want } \\
\text { to-what you want to }\end{array}$ \\
\hline \multicolumn{3}{|l|}{ Adverbial clause fragment } \\
\hline $\begin{array}{l}\text { Pronoun / noun phrase }+ \\
\text { be }(+\ldots)\end{array}$ & $\begin{array}{l}\text { This is going to-I am going to-we are } \\
\text { going to-so I'm going to- that is } \\
\text { going to }\end{array}$ & This is going to \\
\hline $\begin{array}{l}\text { Others(dependent clause } \\
\text { fragments }\end{array}$ & $\begin{array}{l}\text { If we have some-let me call this-so } \\
\text { let us say-If you look at-If I look at- } \\
\text { am going to have-are going to have- } \\
\text { I'm going to have }\end{array}$ & $\begin{array}{l}\text { let's say you Have-You look at this- } \\
\text { have a lot of-if you look at-so you want } \\
\text { to make-going to be equal-what do we } \\
\text { do-have to worry about-you want to } \\
\text { make-you want to use-you want to do- } \\
\text { going to look like-You're going to have }\end{array}$ \\
\hline
\end{tabular}



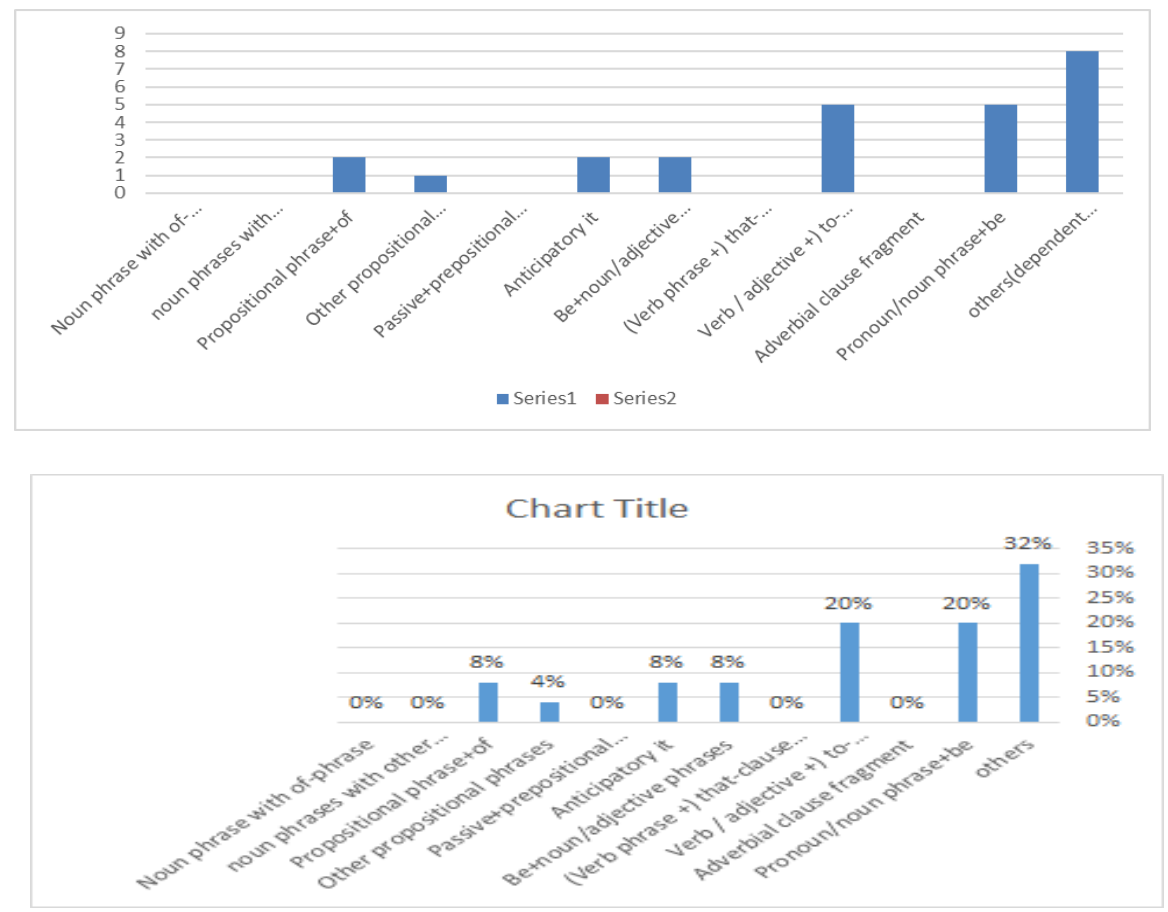

Figure1. Distribution of the structural types of lexical bundles in non-native lecturers' lectures

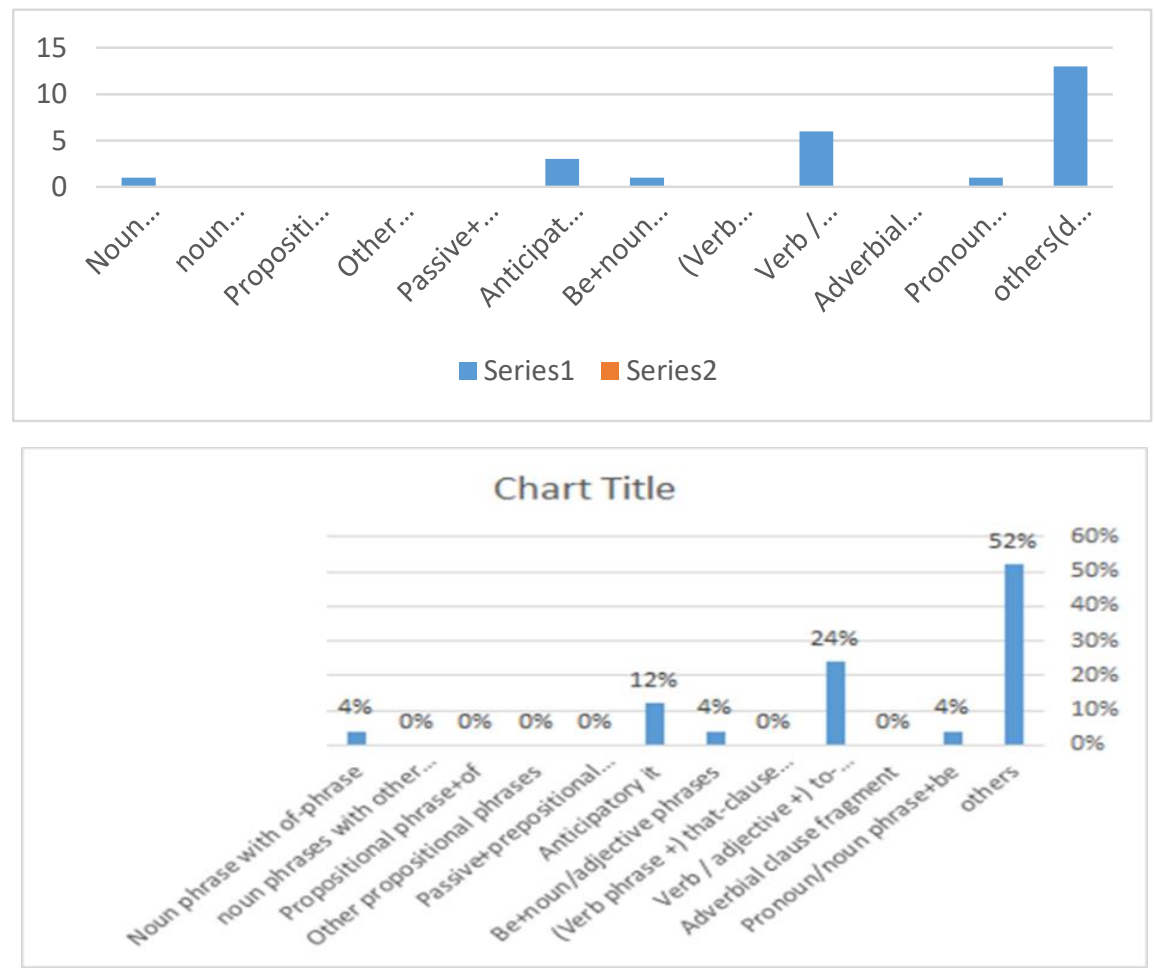

Figure 2. Distribution of the structural types of lexical bundles in native lecturers' lectures 


\subsubsection{Verb Structure}

A more detailed look at figures 1 and 2 shows that the second most commonly used lexical bundles is different kinds of verb structures in both corpora. The verb structures classified under this category are four subcategories.

Table 7. Verb structure in NNLLs and NLLs

\begin{tabular}{ccc}
\hline Anticipatory it & It is going to-So it is like & $\begin{array}{c}\text { It's going to be-It's going to } \\
\text { look-It's kind of like }\end{array}$ \\
\hline $\begin{array}{c}\text { Be+noun/adjective phrases } \\
\text { Verb / adjective +) to-clause } \quad \text { fragment }\end{array}$ & $\begin{array}{c}\text { Is going to be-Is some kind of } \\
\text { Will be able to- I would like to-So } \\
\text { I have to-If I try to-If I want to, }\end{array}$ & $\begin{array}{c}\text { Is going to be } \\
\text { You really want to-We don't } \\
\text { need to-If you want to-What you } \\
\text { want to }\end{array}$ \\
Pronoun/noun phrase+be & $\begin{array}{c}\text { This is going to-I am going to-We } \\
\text { are going to-So I'm going to- That } \\
\text { is going to }\end{array}$ & \begin{tabular}{c} 
This is going to \\
\hline
\end{tabular} \\
\hline
\end{tabular}

Verb structures formed $56 \%$ and $42 \%$ of the whole explored lexical bundles in NNLLs and NLLs, respectively. The majority of verb structures used in NNLLs were Pronoun/noun phrase + be and Verb /adjective +) to-clause fragment but in NLLs it was Verb / adjective +) to-clause fragment and Anticipatory it. The significant point in verb structure analyzing is that verb phrases with non-passive verbs are only phrases that have been used in these two corpora while there was no example of a passive verb phrase in either sub-corpus. This finding may be due to the fact that speech relies mostly on more direct physical context to convey the meaning or message. Lecturers in two groups chose active verbs as the simplest and the most straightforward structures to deliver their lessons. Active verbs help comprehension of the given lectures.

4.3 Functional Characteristics of Lexical Bundles

The target lexical bundles were classified in terms of their functions according to a modified version of Hyland's (2008a) functional taxonomy that is demonstrated in the following table.

Table 8. Functional taxonomy of target bundles (adapted from Hyland, 2008a, pp. 13-14)

A. Research-oriented bundles: Help writers to structure their activities and experiences of

the real world

Location: Indicating time/place: Indicate place, extremity, and direction at the end of, at the same time

Procedure: Indicating events, actions, and procedures the use of

Quantification: Indicate measures, quantities, and proportions a wide range of

Description: Indicate quality, degree, and existence the structure of the

Grouping: Indicate groups, categories, parts and orders a group of 
B. Text-oriented bundles: Concerned with the organization of the text and its meaning as a message or argument

Additive: Establishing additive or contrastive links between elements

Comparative: Compare and contrast different elements

Inferential: signal inferences and conclusions drawn from data

Causative: Mark cause and effect relations between elements on the other hand

in contrast to

we concluded that

as a result of

Structuring: Text-reflexive markers that organize stretches of discourse or direct the reader elsewhere in the

Text

Framing: Situate arguments by specifying limiting conditions

Citation: Cite sources and supporting data

Generalization: Signal generally accepted facts or statements

Objective: Introduce the writer's aim as described previously

with respect to

as reported previously

is thought to be

in order to

C. Participant-oriented bundles: Focused on the writer or reader of the text

Stance: Convey the writer's attitudes and evaluations

Engagement: Address readers directly

Acknowledgment: Recognizing people or institutions that have participated in or contributed to the study kindly provided by are likely to be

It should be noted that

In Table 9, Figures 3 and 4 we can see the functional classification of the two sub-corpus according to this taxonomy and the graphs that show the frequency of each category for each group separately.

Table 9. Functional taxonomy of target bundles

\begin{tabular}{|c|c|c|}
\hline Function & NNTLs & NTLs \\
\hline \multicolumn{3}{|l|}{$\begin{array}{r}\text { Research oriented } \\
\text { bundles }\end{array}$} \\
\hline Location & In the middle of & The end of the \\
\hline \multicolumn{3}{|l|}{ Procedure } \\
\hline \multicolumn{3}{|l|}{ quantification } \\
\hline Description & In the form of & \\
\hline \multicolumn{3}{|l|}{ Grouping } \\
\hline Text-oriented bundles & & \\
\hline Additive & & \\
\hline
\end{tabular}


comparative

Inferential

Causative

structuring

As far as the

Framing

Citation

Generalization

if we have some

Objective If I try to-Let me call this-So let us say

To do is to-So what do we-

Have a lot of

\section{Participant-oriented}

bundles

Stance

engagement

Acknowledgment
Is going to be-Is some kind of

-It is going to-That is going to-Are going to have-So it Is like- Will be able to

This is going to-Am going to have-

I am going to-If I want to-I would like toSo I have to-I'm going to have

-So I'm going to-We are going to-If you look at-If I look at-
Is going to be-It's going to be-Going to have to-Going to be equal-This is going to

-Going to look like-It's going to look-It's kind of like-You really want to-What you want to-You want to Use-You want to doYou want to Make-You're going to have You look at This-If you want to-If you look at -Have to worry about-Let's say you have We don't need to-what do we do 


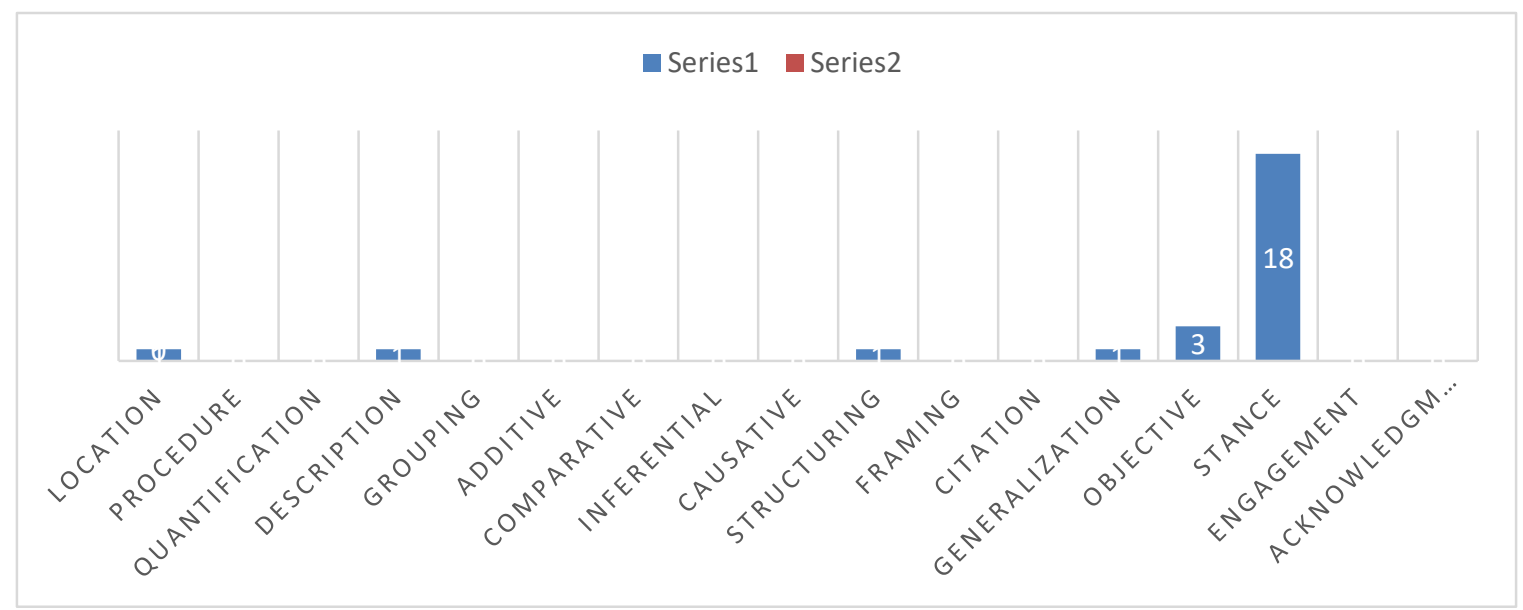

Figure 3. Functional taxonomy of NNLLs

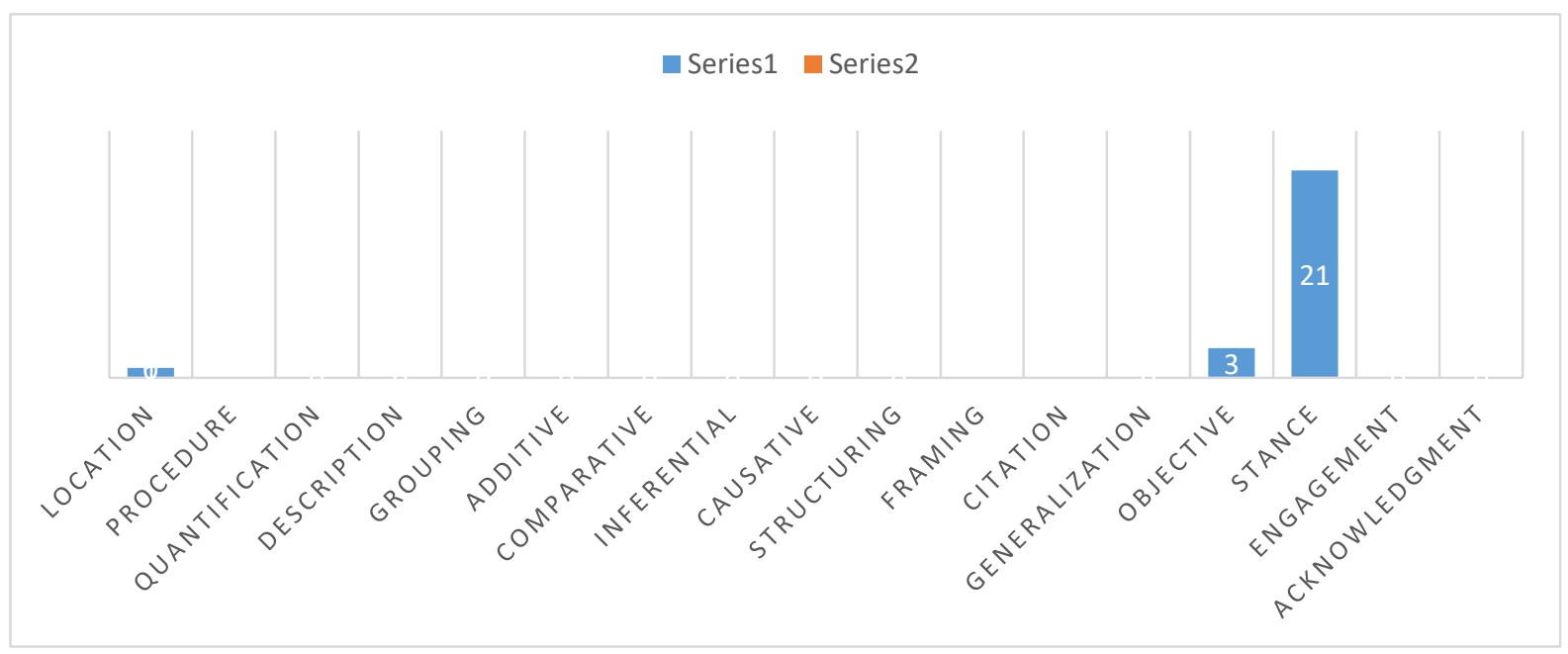

Figure 4. Functional taxonomy of NNLLs

Native and non-native lecturers both employed Participate-oriented bundles more than the other two categories in their lectures. The percentage of this category is $84 \%$ and $72 \%$ of the whole identified bundles in NLLs and NNLLs, respectively. Stance sub-category stands on the top. This finding appears to be common in a variety of academic spoken registers. As Biber et al. (2004) and Biber and Barbieri (2007) also revealed that in conversations, stance expressions accounted for over $60 \%$ of the bundles in their corpora. One of the most significant results of this study is the similarity in the use of stance expressions by both native and non-native lecturers only with a slight difference in numbers. If we look at these bundles classification in more details, we can see in line with the previous studies, mostly stance bundles in spoken registers, such as conversations and classroom teaching, are used to demonstrate the attitudes and assessment of the lecturers towards the lectures. According to functional category presented by Biber et al. (2004), stance bundles are divided into two sub-categories that makes it easier to determine and analyze them. Table 10 will show these sub-categories. 
Table 10. Sub-categories of stance lexical bundles (Biber et al., 2004)

\begin{tabular}{cc}
\hline Stance bundles & Sub-categories \\
\hline A & Epistemic stance \\
B & Attitudinal/modality stance \\
B1 & Desire \\
B2 & Obligation/directive \\
B3 & Intention/prediction \\
B4 & Ability \\
\hline
\end{tabular}

We can classify our identified stance lexical bundles in each corpus according to this classification. In Table 11, Figures 5 and 6, the distribution of identified stance bundles in two corpora are shown respectively.
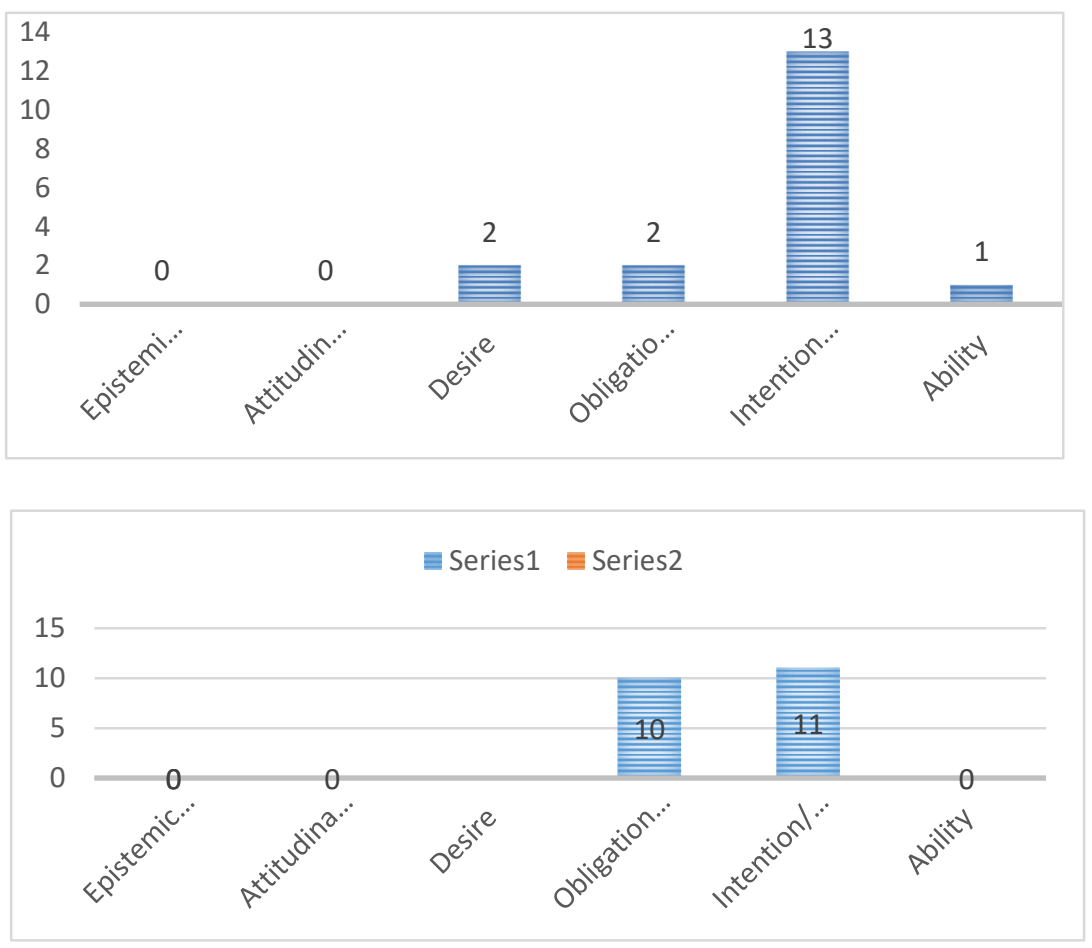

Figure 6. Distribution of stance lexical bundles in NLLs 
Table 11. Distribution of identified stance lexical bundle in NNLLs and NLLs

\begin{tabular}{llc} 
Stance' Sub-category & NNLLs & NLLs \\
\hline
\end{tabular}

Epistemic stance

\begin{tabular}{cl}
\hline Attitudinal/modality & \\
\hline Desire & If I want to-I would like to \\
\hline Obligation/directive & So I have to-if you look at
\end{tabular}

Have to worry about- We don't need to- You look at This- If you look atYou really want to-What you want to-You want to Use-You want to doYou want to Make- Let's say you have

Intention/prediction Is going to be-is some kind of-it is going to-that is going to-are going to have-so it is like-this is going to-Am going to have-I am going to-I'm going to have-so I'm going to-we are going to-if I look at-
Is going to Be-It's going to be-

Going to have to-Going to be EqualThis is going to-Going to look likeIt's going to look-it's kind of likeyou're going to have- What do we do-If you want to-

Ability Will be able to

By looking at these two figures we can see that attitudinal/modality stance is the only sub-category that is used by both groups. Non-native lecturers use intention/prediction sub-category more frequently and the using frequency of other categories is almost the same, but Native lecturers use only two sub-categories of Attitudinal/modality including intention/prediction and obligation/directive. As have been stated before, in two groups, intention/prediction seems to be the most common stance lexical bundles used. The remarkable occurrence of such bundles in these two corpora could be attributed to the nature of academic lectures being teacher-centered and in live situation. In this situations, students do not have time to process information rapidly so they are needed to be informed continually of the new plans or events.

Native lecturers in comparison with non-native ones use obligation/directive stance bundles more frequently. This kind of bundles mostly is used to attract the students' attention towards an object according to the topic of the lectures or to make them perform some actions based on the instructions and procedures presented in the lecture. Looking at this table in detail demonstrates that identified lexical bundles in this sub-category is used as direction stance bundles. These directive bundles were used as topic introduction like if you look at. This will help student to follow the lecturer topic and not becoming confused which is not used by non-native lecturers.

As we can see research-oriented bundles are rarely used by both native and non-native lecturers. This is due to the fact that the nature of this bundles refers to the structural superiority of noun phrase + of fragments structural classifications. Research-oriented bundles mostly have this structure. Therefore, the more the number of this kind of lexical bundles, the higher the probability of its related function will be. As stated before noun phrases were rarely used by two groups of lecturers in this study so obviously the identified lexical bundles could not be assigned to this category.

Text-oriented bundles make up 20\% and $12 \%$ of the whole identified lexical bundles in the NNL and NL corpuses respectively. This shows that native and non-native lecturers used text-oriented bundles as a facilitator towards more text cohesion. In other words, they utilize these bundles in order to connect different elements in the lectures, set conditions and limitations, contextualize their ideas, and validate their own interpretations. Text-oriented bundles on 
the other hand are defined as those bundles concerned with organization of the lecture through which a massage or an argument is conveyed. An interesting finding in this study was the absence of many of the functional sub-categories in both native and non-native lectures.

\section{Discussion}

As the researcher said in the previous sections, the goal in this study is to compare lexical bundles in hard science lectures in case of native and non-native university lecturers in terms of frequency and function to find the differences between these two groups to help lecturers and students identify the most common lexical bundles and their functions used by native lecturers and apply them in their speech. To make this research generalizable, the researcher needed to have easy access to the data bases but due to problems of reaching these kinds of data bases; the researcher had to limit corpus. The findings showed that despite expectations, the lexical richness of NLLs was lower than NNLLs. Although due to the small size of corpus the researcher cannot give a general conclusion regarding to this issue, it can be concluded that university classes even with native lecturers cannot expose non-native students to rich lexical environment. So despite the fact that exposing students to more lexical bundles can increase their English proficiency, this result will strengthen this idea that university lecturers are merely trying to cover course syllables and do not consider this capability of the university classes.

In terms of structural classification, it can be seen that others (Dependent clause fragment) were the most widespread structures of the identified lexical bundles in the Native and Non-Native lecturers' lectures. The majority of verb structures used in NNLLs were Pronoun/noun phrase+be and Verb / adjective +) to-clause fragment but in NTLs it was Verb / adjective +) to-clause fragment and Anticipatory it. The remarkable point in verb structure analyzing is that verb phrases with non-passive verbs are only phrases that have been used in these two corpora while there was no example of a passive verb phrase in either sub-corpus. This finding may be due to the fact that speech relies mostly on more direct physical context to convey the meaning or message.

About the functional classification of the identified lexical bundles, it should be mentioned that the most commonly employed function by both NL and NNL was Stance bundles. Native and Non-Native lecturers employed intention/prediction with the highest frequency higher than other functions in their lectures and research-oriented bundles are rarely used by both native and non-native lecturers.

Findings also showed that the percentages of using K1 and K2 level words and AWL by both native and non-native lecturers are almost the same. It shows that non-native lecturers are as familiar with these kinds of words as native lecturers. The results reveal that there are similarities in using lexical bundles by Native and Non-Native lecturers that could be suitable for non-native lecturers who teach in international universities since being closer in using lexical bundles to NL can help their students to learn the appropriate way of using these bundles in their talks which is one of the goals of this study (Kashiha \& Heng, 2013). As it was seen in other studies such as Katiraei and Eslami Rasekh (2014) NNLs used complete form of the verbs like it is, this is but NL used to use contractions of the verbs like it's, I'm going, and like this.

If we want to compare this result with the same researches in this area on soft science (Kashiha \& Swee Heng, 2013), it can be seen that the fact that in soft science, noun and propositional phrase fragments were the most common structures, might have resulted from the expressive nature of the disciplines that required the lecturers to use a greater variety of short phrases, including different noun and propositions to best convey their messages. The frequent use of clause category may demonstrate consistent features of spoken discourse which included more clausal lexical bundles in spontaneous conversations (Biber \& Bibiery, 2007; Biber \& Conrad, 1999; Biber et al., 1999, 2004).

It should be mentioned that this finding is similar to the findings of the previous studies done by Biber et al. (2004) and Heng, Kashiha, and Tan (2014). Biber et al. (2004) investigated the use of lexical bundles in university classroom teaching and textbooks. This previous study provides a finding that almost $90 \%$ of all common lexical bundles incorporate verb phrases. The findings of this study also confirm this result.

The last point that should be mentioned is that using obligation/directive sub-category by NLs makes students to be concerned in the classroom activity, especially in university classes that usually there is not enough time for lecturers and students to communicate a lot and lecturers want to cover all the syllabus so monologue is the only kind of speech that takes place in the classroom, if the lecturers use 2nd pronouns, they can attract students' attention more easily. Also this makes the students to think that they are part of the activity that the lecturer is lecturing on (Fitriati \& Wahyuni, 2019). 
To the author's knowledge, a very serious problem that is related to native and non-native lecturers in international universities is that they do not consider this fact that along with teaching course syllabus, it is also important for international students to be exposed to a variety of lexical bundles to get familiar with the common function and structures of them and to learn where and when should use them. So improving richness of lexical bundles in lecturers' talk can satisfy this goal since lecturers' talk can give new insights into the development of lexical competence and, more precisely, differences in the quality of students' language.

The structural and functional analysis of our corpora should be presented to novice lecturers using the language, especially when they use English as their second language. Efficient use of these bundles improves better engagement with the students. Lectures delivered without instances of lexical bundles in the right position (functionally and structurally) might make them to be too formal and invariable in tone and rhythm that was obvious in non-native lectures' lectures (recorded voices). It should be mentioned that in transcribing the recorded voice, it was obvious that NNLs use more hesitation markers in their talks. As a result, two different recorded voices from NL and NNL lead to a text with a remarkable difference in the number of words so to speak naturally and effectively, lecturers have to use variety of lexical bundles which embed a variety of functions by themselves. Different lexical bundles preferences suggest specific lexical bundles that NNLs need to learn in order to teach more fluently.

\section{Conclusion}

Based on the analysis and discussion of the present study, there are some conclusions that can be drawn. Structurally, non-native and native English lecturers performed lexical bundles mostly in form of verb phrase, dependent clause, and rarely in form of noun phrase and prepositional phrase. However, they used dependent clause fragments the most. Similarly, both lecturers employed lexical bundles in form of verb phrase. Functionally, they both performed lexical bundles as stance expressions. Yet, even though both groups of lecturers employed the same structure and function, they are different in terms of the subcategories. There is a close relationship between the structures of lexical bundles and the function they serve. Frequently, lexical bundles in form of verb phrase can function as stance expressions. The conclusions explained above lead the researcher to provide some suggestions. In teaching and learning process, it is important for lecturers to use lexical bundles in the talk as well as to raise their awareness in performing the correct bundles structurally and functionally. The use of lexical bundles in the talk will facilitate the acquisition process of the students. It is also obligatory for non-native lecturers to adopt some bundles performed by the native English lecturers to make their talk sound natural and fluent.

\section{References}

Ädel, A., \& Erman, B. (2012). Recurrent word combinations in academic writing by native and non-native speakers of English: A lexical bundles approach. English for Specific Purposes, 31(2), 81-92. https://doi.org/10.1016/j.esp.2011.08.004

Biber, D. (2006). University language: A corpus-based study of spoken and written registers. Amsterdam: Benjamin.

Biber, D., \& Barbieri, F. (2007). Lexical bundles in university spoken and written registers. English for Specific Purposes, 26(3), 263-286. doi:10.1016/j.esp.2006.08.003

Biber, D., \& Conrad, S. (1999). Lexical bundles in conversation and academic prose. In H. Hasselgard, \& S. Oksefjell (Eds.), Out of corpora (pp. 181-190). Amsterdam: Rodopi.

Biber, D., Conrad, S., \& Cortes, V. (2004). If you look at ...: Lexical bundles in university teaching and textbooks. Applied Linguistics, 25(3), 371-405. https://doi.org/10.1093/applin/25.3.371

Biber, D., Johansson, S., Leech, G., Conrad, S., \& Finegan, E. (1999). Longman grammar of spoken and written English. London: Longman.

Chen, L. (2008). An investigation of lexical bundles in electrical engineering introductory textbooks and ESP textbooks. ProQuest, UMI Dissertations Publishing.

Conrad, S., \& Biber, D. (2004). The frequency and use of lexical bundles in conversation and academic prose. Lexicographica, 20, 56-71. doi: 10.1515/9783484604674.56 
Cortes, V. (2004). Lexical bundles in published and student disciplinary writing: Examples from history and biology. English for Specific Purposes, 23(4), 397-423. https://doi.org/10.1016/j.esp.2003.12.001

Crossly, S. A., \& Salsbury, T. (2011). The development of lexical bundle accuracy and production in English second language speakers. IRAL, 49(1), 1-26. https://doi.org/10.1515/iral.2011.001

Dang, T. (2018). The nature of vocabulary in academic speech of hard and soft-sciences. English for Specific Purposes, 51, 69-83. https://doi.org/10.1016/j.esp.2018.03.004

Ellis, N. C. (2002). Frequency effects in language processing: A review with implications for theories of implicit and explicit language acquisition. Studies in Second Language Acquisition, 24(2), 143-188. doi: https://doi.org/10.1017/S0272263102002024

Ellis, R. (2005). Principles of instructed language learning. System, 33(2), 209-224. https://doi.org/10.1016/j.system.2004.12.006

Esfandiari, R., \& Barbary, F. (2017). A contrastive corpus-driven study of lexical bundles between English writers and Persian writers in psychology research articles. Journal of English for Academic Purposes, 29, 21-42. https://doi.org/10.1016/j.jeap.2017.09.002

Fitriati, S., \& Wahyuni, S. (2019). Lexical bundles in WhatsApp conversation between native and non-native speakers of English. Advances in Social Science, Education and Humanities Research (ASSEHR), 188. https://doi.org/10.2991/eltlt-18.2019.61

Granger, S., \& Paquot, M. (2010). Customising a general EAP dictionary to meet learner needs. In Granger, S. \& M. Paquot (eds) (2010) eLexicography in the 21st century: New challenges, new applications. Louvain-laNeuve, Presses universitaires de Louvain, 87-96.

Heng, C. S., Kashiha, H., \& Tan, H. (2014). Lexical bundles: Facilitating university "Talk" in group discussions. English Language Teaching, 7(4), 1-10. doi:10.5539/elt.v7n4p1 http://dx.doi.org/10.5539/elt.v7n4p1

Hyland, K. (2008a). As can be seen: Lexical bundles and disciplinary

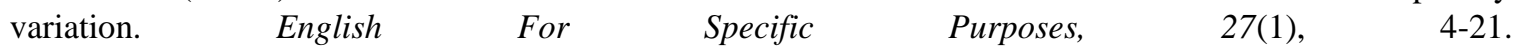
https://doi.org/10.1016/j.esp.2007.06.001

Hyland, K. (2008b). Academic clusters: Text patterning in published and postgraduate writing. International Journal of Applied Linguistics, 18(1), 41-62. https://doi.org/10.1111/j.1473-4192.2008.00178.x

Hyland, K. (2012). Bundles in Academic Discourse. Annual Review of Applied Linguistics, 32, 150-169. doi: https://doi.org/10.1017/S0267190512000037

Jalali, H., Eslami Rasekh, A., \& Tavangar Rizi, M. (2008). Lexical bundles and intradisciplinary variation: The case of applied linguistics. Iranian Journal of Language Studies, 2(4), 447-484.

Kashiha, H., \& Heng, C. S. (2013). An exploration of lexical bundles in academic lectures: Examples from hard and soft sciences. The Journal of Asia TEFL, 10(4), 133-161. https://www.researchgate.net/publication/288655820_An_exploration_of_lexical_bundles_in_academic_le ctures_Examples_from_hard_and_soft_sciences

Kashiha, H., \& Heng, C. S. (2014). Discourse functions of formulaic sequences in academic speech across two disciplines. Journal of Language Studies, 14(2), 15-27. http://dx.doi.org/10.17576/GEMA-2014-1402-02

Kazemi, M., Katiraei, S., \& Rasekh, A. E. (2014). The impact of teaching lexical bundles on improving Iranian EFL students' writing skill. Procedia-Social and Behavioral Sciences, 98(6), 864-869. https://doi.org/10.1016/j.sbspro.2014.03.493

Krashen, S. (1981). Second language acquisition and second language learning. Oxford: Pergamon Press. 
Krashen, S. (1982). Principles and practice in second language acquisition. Oxford: Pergamon Press.

Kwon, Y. E., \& Lee, E. J. (2014). Lexical bundles in the Korean EFL teacher talk corpus: A comparison between nonnative and native English teachers. The Journal of Asia TEFL, 11(3), 73-103. http://journal.asiatefl.org/main/main.php?inx_journals=41\&inx_contents=61\&main $=1 \&$ sub $=2 \&$ submode $=3$ $\&$ PageMode=JournalView\&s_title=Lexical_Bundles_in_the_Korean_EFL_Teacher_Talk_Corpus_A_Com parison_Between_Non_native_and_Native_English_Teachers

Lorenna, M., Fitriati, S., \& Widhiyanto. (2020). The comparison of lexical bundles in EFL teachers' talk between non-native and native English teachers. English Educational Journal, 10(1), 69-75. doi: 10.15294/EEJ.V10I1.33830

Malik, M. A., Fazal, H., \& Moavia, H. (2019). Formulaic language in social sciences: A functional analysis of lexical bundles in native and non-native academic discourse. Pakistan Social Sciences Review, 3(1), $234-249$. https://pssr.org.pk/issues/v3/1/formulaic-language-in-social-sciences-a-functional-analysis-of-lexicalbundles-in-native-and-non-native-academic-discourse.pdf

Neely, E., \& Cortés, V. (2009). A little bit about: analyzing and teaching lexical bundles in academic $\begin{array}{llll}\text { lectures. Language } & \text { Value, } & 1(1), & 17-38 .\end{array}$ revistes.uji.es/index.php/languagevalue/article/view/4731

Nesi, H., \& Basturkmen, H. (2006). Lexical bundles and discourse signaling in academic lectures. International Journal of Corpus Linguistics, 11(3), 283-304. doi: https://doi.org/10.1075/ijcl.11.3.04nes

Rezoug, F., \& Vincent, B. (2018). Exploring lexical bundles in Algerian corpus of engineering. Arab Journal of Applied Linguistics, 4(4), 47-77. https://files.eric.ed.gov/fulltext/EJ1207967.pdf

Salazar, D. (2014). Lexical bundles in native and non-native scientific writing: Applying a corpus-based study to language teaching (Vol. 65). Amsterdam: John Benjamins Publishing Company.

Schnur, E. (2014). Phraseological signaling of discourse organization in academic lectures: a comparison of lexical bundles in authentic lectures and EAP listening materials. Year Book of Phraseology Journal, 5(1), 95-122. https://doi.org/10.1515/phras-2014-0005

Shin, Y. K. (2019). Do native writers always have a head start over nonnative writers? The use of lexical bundles in college students' essays. Journal of English for Academic Purpose, 40(3), 1-14. https://af.booksc.org/book/75169883/e44527

Tang, E. (2011). Non-native teacher talk as lexical input in the foreign language classroom. Journal of Language Teaching and Research, 2(1), 45-54. doi:10.4304/j1tr.2.1.45-54

Üstünlüoglu, E. (2007). University students' perceptions of native and non-native teachers. Teachers and Teaching: theory and practice, 13(1), 63-79. https://doi.org/10.1080/13540600601106096

VanPatten, B. (2003). From input to output: A teacher's guide to second language acquisition. New York: McGrawHill.

Vidal, K. (2003). Academic listening: A source of vocabulary acquisition? Applied Linguistics, 24(1), 56-89. https://doi.org/10.1093/applin/24.1.56

VO, S. (2019). Use of lexical features in non-native academic writing. Journal of Second Language Writing, 44(3), 1-12. https://doi.org/10.1016/j.jslw.2018.11.002

West, M. (1953). A general service list of English words: with semantic frequencies and a supplementary word-list for the writing of popular science and technology. London: Longman.

Wood, D. (2015). Fundamentals of formulaic language. London: Bloomsbury Academic.

Wray, A. (2002). Formulaic language and the lexicon. Cambridge: Cambridge University Press. 